\title{
Measuring Adaptive Expertise in Engineering Education
}

\section{Dr. Olga Pierrakos, James Madison University}

Olga Pierrakos is a Founding Faculty and Associate Professor in the Department of Engineering at James Madison University. She is currently a Program Director at the National Science Foundation in the Division of Undergraduate Education. Her expertise and interests focus on diversity and inclusion, engineer identity, PBL, innovative learning-centered pedagogies, assessment of student learning, engineering design, capstone design, etc. She also conducts research in cardiovascular fluid mechanics and sustainable energy technologies. She holds a BS and MS in Engineering Mechanics and a PhD in Biomedical Engineering from Virginia Tech.

\section{Dr. Robin Dawn Anderson, James Madison University}

Robin D. Anderson serves as the Academic Unit Head for the Department of Graduate Psychology at James Madison University. She holds a doctorate in Assessment and Measurement. She previously served as the Associate Director of the Center for Assessment and Research Studies at JMU. Her areas of research include assessment practice and engineering education research.

\section{Cheryl Alyssa Welch}

Alyssa Welch is a Psychological Sciences master's student in the concentration of Experimental Psychology, and a Graduate Teaching Assistant in the Department of Psychology at James Madison University. She received her BA in Psychology and Anthropology from James Madison University as well. As a graduate assistant, she is currently working closely with the engineering department performing interdisciplinary research with the goal of improving engineering programs at the undergraduate level. Her research interests include adaptive expertise, metacognition, social influence, cognitive dissonance, and social neuroscience. 


\title{
Measuring Adaptive Expertise in Engineering Education
}

\author{
Olga Pierrakos ${ }^{a}$, Cheryl Alyssa Welch ${ }^{\text {, }}$, and Robin D. Anderson ${ }^{b}$ \\ Department of Engineering ${ }^{a}$, Department of Graduate Psychology ${ }^{b}$ \\ James Madison University \\ Harrisonburg, VA, USA
}

\begin{abstract}
With the rapid pace of technological change, the environment that future engineers will face will require the ability to adapt quickly and engage in novel problem solving. Adaptive expertise is defined as the ability to apply knowledge, gained through prior experiences, to novel situations in which key information is missing. Researchers have attempted to measure adaptive expertise through a variety of methods including interviews, think-alouds, assignment-specific classroom assessments and self-report belief surveys. One of the most commonly used measures is Fisher and Peterson's Adaptive Expertise Beliefs survey ${ }^{[1]}$. As part of a larger post-semester survey, researchers at a mid-Atlantic university administered Fisher and Peterson's Adaptive Expertise Beliefs survey ${ }^{[1]}$ to students enrolled in two sections of a senior design capstone course. Instructors taught one section of the course using methods based on the principles of adaptive expertise, while the other course section involved the use of the traditional lecture-based method of instruction. Results indicated a significant difference in overall adaptive expertise belief scores. However, researchers did not find significant differences between the two groups on any of the individual Fisher and Peterson subscales, making interpretations regarding the impact of instructional methodology more difficult and less useful to the instructors. Given the importance of adaptive expertise to the emerging engineer, it is imperative that a measure of adaptive expertise be able to provide meaningful information regarding how students perform on the various dimensions of the construct. This paper argues for the development of a more sensitive, more direct measure of adaptive expertise that can be used across different design challenges.
\end{abstract}

\section{Keywords}

adaptive expertise, beliefs, measurement, assessment

\section{MOTIVATION \& PURPOSE OF STUDY}

Undergraduate engineering programs in the United States are facing the demands of global competitiveness, outsourcing, and an increase in production of overseas engineers. Adaptive expertise is a skill set that would support students' preparation for the complex problem solving environments of the real-world. The display of adaptive expertise has been said to "ultimately lead to students' depth of knowledge and habits of mind that lead to success in their career and enable them to be innovators in the field" ${ }^{[2]}$. For this reason, it is important for educators and scholars to explore how we can better prepare our students to showcase adaptive expertise. It is equally important to assess the effectiveness of our attempts at facilitating this development.

Think-a-louds, ${ }^{[3]}$ interviews ${ }^{[1]}$, and self-report surveys ${ }^{[4][1][5][6][7]}$ have all been used to measure adaptive expertise, with the most common method of measurement being the Adaptive Expertise Beliefs Survey. The current study aims to examine whether a difference in adaptive 
expertise, as measured by the Adaptive Beliefs Survey, exists between two separate design course sections. One of which was guided by adaptive expertise principles while the other consisted of traditional lecture based course. The question guiding this research is:

Do teaching methods guided by adaptive expertise principles promote the development of adaptive expertise in students more so than traditional lecture based methods?

We predicted that responses on the Adaptive Expertise Beliefs Survey ${ }^{[1]}$ from students in the adaptive expertise-based design course section would indicate more adaptive expertise than responses from students in the traditional lecture-based design course section.

\section{THEORETICAL BACKGROUND OF ADAPTIVE EXPERTISE}

In 1986, Giyoo Hatano and Kayoko Inagaki developed a seminal framework for adaptive expertise ${ }^{[8]}$. They distinguished between two forms of expertise: routine and adaptive. Routine experts refer to experts who have become highly efficient by habitual usage of knowledge in a specific domain and a high amount of experience. Adaptive experts, on the other hand, refer to experts that have the ability to balance efficiency with innovation. In the framework, efficiency refers to "speed, accuracy, and automaticity of solving familiar problems" while innovation is described as "flexible, innovative, and creative competencies" [9]. This balance permits adapting previous knowledge into new situations while remaining productive and efficient. Derived from Piaget's theory on cognitive development ${ }^{[10]}$, adaptive expertise, for the purpose of this study, is defined as the ability to apply knowledge gained through prior experiences to novel situations in which key parts of information are missing ${ }^{[5]}$.

Adaptive expertise is achieved when a person attains high levels of both innovation and efficiency. In this orthogonal relationship model (see Figure 1), an adaptive expert is not simply the next level above a routine expert in a linear progression but instead a completely different type of expert. This relationship is well illustrated in Wineburg's study ${ }^{[11]}$ comparing two historians. The two historians were given an exercise in which they were asked to study a set of historical documents from Abraham Lincoln's era and then use the documents to formulate an understanding of Lincoln's view on race. Expert 1 was a content expert who specialized on Abraham Lincoln and the Civil War, while Expert 2 was a general historian. Results showed that Expert 2 performed much better on the task by using the cognitive skills that promoted adaptability. Expert 2 used strategies associated with positive learning ${ }^{[1]}$ such as the use of questions, looking for alternative hypotheses, assessing his own performance, and evaluating the situation throughout the process. Expert 1 had revealed routine precision in approaching the problem and relied heavily on his content specific foreknowledge. While this may be perceived as an advantage, the heavy reliance on procedural knowledge resulted in oversight. The extensive familiarity with the topic that Expert 1 possessed actually handicapped his approach, not allowing for innovative thought or the transfer of knowledge and strategy ${ }^{[11]}$. 


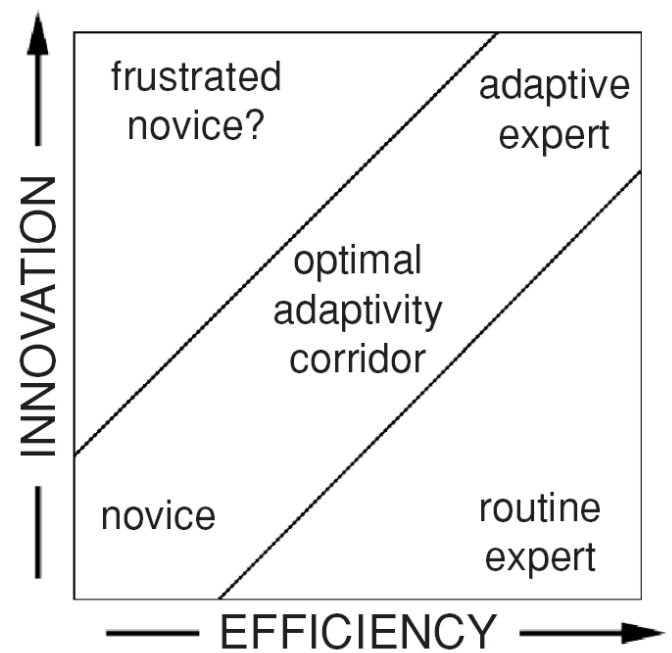

Figure 1. Adaptive Expertise and the Orthogonal Relationship of Efficiency and Innovation. Note: retrieved from Reed (2015)

\section{ADAPTIVE EXPERTISE IN ENGINEERING EDUCATION}

Researchers in engineering education have been striving to find the best methodology for preparing students for success in their future careers. "While basic schools cannot make students real experts, they can place students on a trajectory toward expertise or prepare them for future learning" [9]. Various researchers have presented the advantages of focusing on the development of adaptive expertise for attaining this goal (see for example ${ }^{[4][3][1][12][9][5][13][6][14][7][15][2]}$ ). McKenna et al. ${ }^{[16]}$ laid out the relationship between adaptive expertise and engineering design education specifically. The design education curriculum consists of both efficiency and innovative components in the learning objectives. Achieving these learning objectives within the design curriculum should help students foster the skills necessary for developing adaptive expertise over time.

However, traditional lecture-based teaching and approaches focused on teaching technical knowledge prevail in engineering classrooms over approaches concerned with skills such as adaptive and innovative problem solving, and critical thinking skills. We posit that these preparation methods and approaches, which are predominantly used in many undergraduate engineering programs, produce skills of routine expertise and but not adaptive expertise. Further, many universities aim for the goals of expertise, yet do not clarify which type of expertise they are trying to develop. This lack of distinction between routine and adaptive expertise also is seen in the methods used to assess expertise. Brophy et al. ${ }^{[2]}$ has discussed this misalignment between stated learning objectives and methods of assessments. For instance, if a stated learning objective associated with a program is to gain adaptive knowledge, most current assessment methods would be inappropriate because the methods assess the procedural skills used by routine experts and not the adaptive components. With a majority of engineering programs including learning objectives related to expertise, new assessment methods need to be created and empirically researched to assess the extent to which adaptive expertise objectives are met. Many researchers have called for methods for measuring adaptive expertise, and some have gone a step further and actually attempted to assess it (for example see ${ }^{[4][2][1][5][13][6][14][15][16]}$ ). 
Pandy et al. ${ }^{[17]}$ investigated the impact of the How People Learn (HPL) framework on students' adaptive expertise of movement biomechanics in a classroom setting. HPL's four principles indicate that the framework is student-centered, knowledge-centered, assessment-centered, and community-centered. To help implement HPL while promoting adaptive expertise, the authors used the STAR-Legacy Cycle which consists of the following stages: The Challenge, Generating Ideas, Multiple Perspectives, Research and Revise, Test Your Mettle, and Go Public. The STARLegacy Cycle allows for feedback and revision, which is necessary for adaptive expertise to occur. Their assessments consisted of pre- and post- questionnaires that measured changes in adaptive expertise. They scored the questionnaires using rubrics for each of their proposed facets of adaptive expertise: factual knowledge ("gauges a student's ability to retain key facts and principles"), conceptual knowledge ("measures a student's ability to grasp the underlying principles of the material taught as well as his or her quantitative skills such as ability to manipulate mathematical symbols and numbers to arrive at the correct answer"), and transfer ("a student's ability to extend his or her knowledge to new and unfamiliar situations ${ }^{[17]}$. Several researchers have taken this pre and post test approach to the assessment of adaptive expertise.

Martin and colleagues ${ }^{[13][6][14]}$ have been conducting research for years on the impact of the How People Learn (HPL) framework on adaptive expertise using pre and post testing. An empirical longitudinal study was conducted to measure adaptive expertise ${ }^{[6]}$. This study was later trailed by two follow up studies ${ }^{[14]}$. Using pre- and post-tests, all of these studies showed evidence that the combination of HPL and the STAR Legacy Cycle increased aspects of adaptive expertise over the common lecture-based model ${ }^{[13][6][14]}$. While the use of pre and post tests allow instructors to examine gains from before to after a specific learning experiences, they require that instructors take away time from instruction to administer the assessment twice. In addition, to track the development of adaptive expertise across the curriculum, one would need multiple equivalent forms of the post assessment. To develop such equivalent forms would require a significant amount of test development knowledge and a great deal of time for development. Thus, self-report surveys, where students are asked to self-report gains, may require less time for both development and administration than pre and post tests. Johnson et al. ${ }^{[5]}$ examined the effects of contextual modeling exercises in CAD on the production of behaviors associated with adaptive expertise. The researchers used a combination of student interviews and responses on a self-report measure in an attempt to assess changes in adaptive expertise. The pre and post interview questions were written specifically to examine the modeling experience. The interviews were transcribed, analyzed and coded in an effort to acquire adaptive expertise manifestation counts. Researchers also used the Adaptive Expertise Beliefs Survey ${ }^{[1]}$ to measure the difference in students' self-reported adaptive expertise skills between a contextual modeling group and control group. Results indicated that there was a positive correlation between the amount of time spent modeling and adaptive expertise behaviors shown in the interview. Responses on the adaptive expertise self-report measure were also positively correlated with increased time of modeling when in contextual exercises ${ }^{[5]}$. These results highlight the importance of context and adaptive expertise qualities when it comes to a student's education. However, the time commitment for the interview collection and analysis process makes the use of interviews across a wide-variety of assignments less practical than belief measures, which can be administered and scored quickly. 


\section{CONTEXT - SENIOR DESIGN COURSES}

The context for this study consisted of two sections of a senior-level engineering design course with an embedded capstone design project. In addition to attending weekly 100-minute meetings to learn about engineering design theory, methods, and tools, students in these courses met outside of class to work on their capstone projects. The model for this course has previously been published previously ${ }^{[18][19][20]}$. The following table showcases some of the differences between the section taught using a more traditional lecture-based format and the section using a format that rewarded adaptive expertise.

\begin{tabular}{|l|c|c|}
\hline \multicolumn{1}{|c|}{ Feature of Course } & $\begin{array}{c}\text { Lecture-Based } \\
\text { Section }\end{array}$ & $\begin{array}{c}\text { Adaptive Expertise- } \\
\text { Based Section }\end{array}$ \\
\hline Content Coverage using a common book & Yes (same) & Yes (same) \\
\hline Chapter Quizzes accompanying lectures & Yes (written) & Yes (oral) \\
\hline Midterm Exam & Yes (written) & Yes (written) \\
\hline Final Exam & No & Yes \\
\hline $\begin{array}{l}\text { Explicit Values of the Course being grit, } \\
\text { metacognition, innovation, collaboration, and quality }\end{array}$ & No & Yes \\
\hline $\begin{array}{l}\text { Optional Prep Guides accompanying each chapter and } \\
\text { guiding students in reading coverage using questions }\end{array}$ & No & Yes \\
\hline $\begin{array}{l}\text { Design Challenges accompanying each chapter and } \\
\text { the theory being learned }\end{array}$ & No & Yes \\
\hline $\begin{array}{l}\text { Mastery-based learning model allowing students to } \\
\text { resubmit work (optional) to show stronger evidence of } \\
\text { mastery learning and to allow for earning points back }\end{array}$ & No & Yes \\
\hline $\begin{array}{l}\text { Common Grading Guide for all assigned focused on } \\
\text { grit (effort), quality, and innovation }\end{array}$ & \multicolumn{2}{|c|}{} \\
\hline
\end{tabular}

More specifically, the following adaptive expertise techniques describe how the classroom environment in the adaptive expertise based section was transformed.

Establishing the Class Culture via Shared and Student-Derived Values and Behaviors - The first day of class began with an activity designed to elicit students' beliefs of workplace expectations (peer to peer expectation, supervisor expectations for employees, employee expectations of supervisor, workplace environment, etc.). What derived from this activity became the expectations for the class. The classroom was envisioned as a workplace environment with a derived set of values and expected behaviors. This activity set the culture and tone for the course and enabled autonomy, relatedness, and competence.

Aligning Effort Contingent Learning and Rewards - Research shows that evaluation practices focused on effort rather than ability trigger mastery learning strategies and better knowledge retention ${ }^{[21]}$. In the classroom, extrinsic rewards are often given with good intentions, but they can have detrimental effects when the rewards are perceived as bribes or controlling ${ }^{[22]}$. When rewards are made contingent on student effort, rewards can enhance achievement-directed behavior and even lead to an increase of task persistence. The treatment group/course was transformed into a classroom where effort was the emphasis to produce quality work and 
perform at high standards. The grading rubric that was developed aligned with this focus on effort and facilitated the evaluation of student work from the point of view of quality of effort. Further, to encourage quality effort and mastery learning, students were allowed to resubmit graded work for a second time in an attempt for students to show deeper understanding and quality effort.

Empowering Students with Autonomy, Self-pacing, and Inductive Teaching Methods - Strategies that allow students to set their own pace with short-term goals or assignment leads to intrinsic motivation. Inductive teaching methods enable students to more effectively solve problems and self-manage goals and their own learning. In the treatment course, a non-traditional pedagogical model was implemented. Interteaching ${ }^{[23]}$, which is new and has been used in psychology but is almost non-existent in STEM education, emphasizes independent learning. Students complete a preparation guide before class that includes reading material and questions. At the beginning of class, the professor clarifies difficult concepts emerging from the previous class. Much of class time is focused on students working/teaching in pairs or small groups. Professors and teaching assistants are available for questions and discussion. At the end of class, students complete a record sheet identifying challenges. Professors use this feedback in preparing for the next lecture.

\section{Using Proactive, Team based Motivational Strategies to Support Team Assignments and} Capstone Projects - Highly valued in competitive athletics, the military, and other fields where qualities such as resilience and persistence are essential to success, team-based strategies are effective in building in-group cooperation. Team cohesion, authentic collaboration, and collective efficacy were frequently discussed in the course with accompanying readings to motivate completion of team assignments and capstone projects. Discussions and activities targeting team performance and "collective efficacy" helped to establish a sense of common experience and purpose in collaborative capstone projects.

\section{METHODOLOGY}

As part of a larger post-semester survey, the Adaptive Expertise Beliefs Survey was administered via Qualtrics to 52 students enrolled in a senior design capstone course at a mid-Atlantic university. Both sections of the design course were included in data collection. One section was taught using methods focusing on the principles of adaptive expertise, while the other course section used the traditional lecture-based method. A sample of 44 surveys were analyzed and compared ( 25 from the AE class, and 18 from the lecture-based class). Eight students were not included in the analysis due to missing data.

\section{A. The Adaptive Expertise Beliefs Survey}

In 2001, Fisher and Peterson identified four foundational constructs of adaptive expertise: multiple perspectives, metacognition, goals and beliefs, and epistemology. The multiple perspectives characteristic illustrates a student's ability to use a wide variety of representations and approaches when working with different problems. Metacognition refers to the process of self-monitoring and self-assessing one's own understanding of their performance in a situation. A student who fully displays the goals and beliefs required to attain adaptive expertise views 
challenges as opportunities for growth and is able to function in shifting climates. Epistemology describes how an individual views knowledge. For instance, students who view knowledge as constantly evolving and who are never satisfied with their current state of knowledge, exhibit the epistemology necessary for developing adaptive expertise ${ }^{[1]}$. Multiple items are reverse coded in order to avoid response bias. High reliability coefficients were found for both the survey as a whole (Cronbach's $\alpha$ between .85 and .89) and for each of the individual subscales (multiple perspectives $\alpha=.77$ to .80 , metacognitive self-assessment $\alpha=.78$ to .79 , goals and beliefs $\alpha=$ .66 to .78 , and epistemology $\alpha=.71$ to .72$)^{[1]}$.

Researchers have used the adaptive expertise beliefs survey to measure adaptive expertise in computer-aided design modeling students ${ }^{[5][7]}$, biomedical engineering students ${ }^{[1]}$, first generation and non-first generation students ${ }^{[7]}$, and special educators ${ }^{[4]}$. Preliminary results from the use of the survey suggested that adaptability increases the longer a student is in school (freshman to senior). Martin and colleagues ${ }^{[6]}$ found increases over the course of a semester, further supporting the influence of time in academia on the development of adaptive expertise. Results from the survey have also been found to be consistent with interview results. Johnson et al. ${ }^{[5]}$ studied the validity of inferences drawn from the survey when measuring the adaptive expertise of biomedical engineering on freshman and junior students, as well as practicing engineers from a Fortune 100 company. Given the support for the survey, the current study sought to investigate if a teaching method based on adaptive expertise principles promoted higher scores on this beliefs survey than the traditional lecture based method.

\section{B. Data Analysis}

A $t$-test analysis was conducted to evaluate if scores from students in the adaptive expertisebased design course section indicate more adaptive expertise on the Adaptive Expertise Beliefs Survey ${ }^{[1]}$ than the scores from students in the traditional lecture-based design course section.

\section{RESULTS AND DISCUSSION}

In the current study, the Adaptive Expertise Beliefs Survey performed consistent with previous research $^{[1]}$. The survey total score showed acceptable reliability $(\alpha=.82)$. All of the subscales also demonstrated acceptable reliability (multiple perspectives, $\alpha=.77$; metacognitive selfassessment, $\alpha=.78$; goals and beliefs, $\alpha=.78$; and epistemology, $\alpha=.79$ ). Despite having a small sample size in the current study, these alpha levels were consistent with the alpha coefficients found in Fisher and Peterson ${ }^{[1]}$. While the total adaptive expertise score in the current study had a slightly lower Cronbach's alpha, all of the subscales were in the same range as found by Fisher and Peterson.

There was a significant difference in the average total adaptive expertise score of students in the adaptive expertise principles-based section $(\mathrm{M}=17.13, \mathrm{SD}=1.53)$ and those in the traditional, lecture-based $(\mathrm{M}=15.93, \mathrm{SD}=1.72)$ section; $(t(42)=2.44, p=.019)$. Results also revealed a practical significance in addition to the statistical significance (Cohen's $\mathrm{D}=.74)$. Interestingly, while the survey showed significant differences between these groups on the total score, the subscales did not show any significant differences. 


\section{CONCLUSIONS AND FUTURE DIRECTIONS}

While the instrument demonstrated acceptable reliability, the information gained from the use of the survey is limited. A comparison of overall expertise shows a significant difference between the two groups. However, without significant differences at the subscale level, we are unable to determine what specific dimensions of adaptive expertise differ across teaching methodologies. A possible lack of sensitivity at the subscale level reduces the amount of information available to the survey user. One possible limiting factor is the self-report nature of the survey. Data from self-report instruments measure what people believe and perceive their behavior to be, not what their behavior actually is. If the question being addressed is inquiring about the level of adaptive expertise one has, a beliefs survey would not answer that question. A more direct measure of adaptive expertise that is psychometrically sound is needed to answer these kinds of inquiries.

\section{A. Self-Report Versus Direct Measure}

When using self-report measures, researchers cannot know if responses to survey items correspond to actual behavior, responders perceptions of their own beliefs, or beliefs regarding what responders believe their behavior should be. This is a common critique of indirect measures such as self-reported surveys. Participants filling out surveys may adjust responses due to social desirability or acquiescence. Social desirability is the tendency for a participant to respond in a socially desirable fashion ${ }^{[24]}$. This tendency can be either conscious or unconscious to the participants. Acquiescence, on the other hand, is the tendency to simply agree with statements as opposed to disagreeing, regardless of being a positive or negative statement ${ }^{[24]}$. Others may be completely honest in their responses without the influence of social desirability, yet still not give accurate data due to recall bias or error in self-perception ${ }^{[25][26][27][28][29][30]}$.

In order to counter and avoid these limitations, a more direct measure of adaptive expertise is needed in order to assess the level of this skill set. Direct measures could consist of direct behavioral observations in either natural settings or in a lab. These observations could occur in person or through a video recording ${ }^{[31]}$. Another form of direct measurement is the observation of products created from the participant being studied. This type of measurement allows us to assess certain attributes through a physical product, eliminating the need to evaluate the process. A direct measure would eliminate the issues of social desirability, acquiescence, and recall bias. It would also remove any ambiguity a beliefs survey creates, allowing us to assess the actual behavior and not just student beliefs or possibly incorrect perceptions of their own behavior. There would be no questions about what was being assessed through the instrument if the instrument was directly measuring an observable behavior or work product. The issue with the direct measures currently used, such as the pre and post tests discussed above, is that they require a significant amount of time to develop and administer.

\section{B. Current Measurements of Adaptive Expertise}

In response to the limitations of self-report questionnaire measures, some engineering education researchers have implemented other methods for the purpose of assessing adaptive expertise, including interviews ${ }^{[1]}$, think-a-louds ${ }^{[3]}$, and rubrics ${ }^{[3][17][15]}$. While interviews can provide more in-depth information than belief surveys, they can also be timely. Each interview must be 
conducted individually to avoid the possibility of social desirability and other influences on the interviewees. Although more direct than a self-report survey or a self-report focused interview, think-alouds also require a considerable amount of time. Like interviews, findings from thinkalouds can be influenced by the subjectivity of the researchers. Also, think-alouds often require an experimental-like setting, instead of occurring naturally in a classroom or group setting.

The most direct method of measurement of adaptive expertise is the use of standardized rubrics to evaluate students' pre-post test responses. A variety of rubrics have been used in an effort to measure adaptive expertise in students and faculty ${ }^{[3][17][15]}$. Pandy et al. ${ }^{[17]}$ created a rubric designed to assess three proposed facets of adaptive expertise: factual knowledge, conceptual knowledge, and transfer. Walker et al. ${ }^{[15]}$ created a rubric designed to examine efficiency, innovation, and confidence as characteristics of adaptive expertise. In 2007, Martin and his colleagues disseminated a rubric designed to measure efficiency and innovation elements in a pre- and post-test. Here in lies another issue with such rubrics; they are designed to assess different conceptualizations of the adaptive expertise construct. These rubrics are designed to score items created for the purpose of assessing a secondary measurement of adaptive expertise (e.g. pre- and post-tests, interviews, and think-a-louds), using various conceptualizations of adaptive expertise. The creation of a rubric that directly assesses the adaptive expertise skill set as it occurs naturally, either through behavioral observation or observation of a product (e.g. a written document), could theoretically be applied across a variety of products designed to demonstrate student learning outcomes. This would allow for comparisons across time as well as across student learning experiences. It could reduce the time demands that interviews, thinkalouds and pre- and post-test assessments create while also providing a more diagnostic, direct measure of adaptive expertise.

\section{Future Research}

Future research should focus on the development of a direct measure of the skill set of adaptive expertise, a measure that can be employed across a variety of written design-related products. Unfortunately, the current adaptive expertise literature lacks a single coherent framework with commonly defined characteristics. After a thorough review of the adaptive expertise literature, our team has identified six primary characteristics of an adaptive expert. The following characteristics were found to be the most common among the adaptive expertise literature: metacognition, multiple perspectives, flexible innovation, multiple representations, epistemology, and conceptual understanding. Further research on these characteristics could create a path for a more direct measurement of adaptive expertise.

\section{Limitations}

While the purpose of this study was clearly a preliminary investigation into the impact of teaching modality on the development of adaptive expertise in the engineering classroom, it quickly became apparent that that the limitations associated with existing adaptive expertise measures limited the inferences researchers could make regarding students' development of adaptive expertise. In addition, the study also involves a small sample size. Despite this limitation, we were still able to identify scale reliabilities that coincided with those found in the development efforts conducted by the survey creators. An additional limitation to the study 
involves the use of different instructors for the two course sections examined in this study. Future studies should use the same instructor to teach both of the course sections being compared. This would assist in minimizing differences in instruction that can influence the content and emphasize provided to the students. A final limitation of this preliminary study is the lack of a baseline. Future research would benefit from collecting pre instruction data from each course section to ensure that pre-existing differences between the two sections do not exist. Confidence in the balance of pre-existing differences between groups would give support to the argument that any differences are due to the teaching method employed in the course section.

[1] Fisher, F. T., \& Peterson, P. L. (2001). A tool to measure adaptive expertise in biomedical engineering students. In Proceedings of the 2001 American Society for Engineering Education Annual Conference, Albuquerque, NM [2] Brophy. S., Hodge, L. \& Bransford, J. (2004, October). Work in progress - Adaptive expertise: Beyond apply academic knowledge. In the ASEE/IEEE Frontiers in Education Conference.

[3] Crawford, V. M., Schlager, M., Toyama, Y., Riel, M., \& Vahey, P. (2005, April). Characterizing adaptive expertise in science teaching. In annual meeting of the American Educational Research Association, Montreal, Quebec, Canada. [4] De Arment, S. T., Reed, E., \& Wetzel, A. P. (2013). Promoting Adaptive Expertise A Conceptual Framework for Special Educator Preparation. Teacher Education and Special Education: The Journal of the Teacher Education Division of the Council for Exceptional Children, 36(3), 217-230.

[5] Johnson, M. D., Ozturk, E., Valverde, L., Yalvac, B., \& Peng, X. (2013). Examining the Role of Contextual Exercises and Adaptive Expertise on CAD Model Creation Procedures. In Human-Computer Interaction. Applications and Services (pp. 408-417). Springer Berlin Heidelberg.

[6] Martin, T., Petrosino, A. J., Rivale, S., \& Diller, K. R. (2006). The development of adaptive expertise in biotransport. New Directions for Teaching and Learning, 2006(108), 35-47.

[7] Peng, X., McGary, P., Ozturk, E., Yalvac, B., Johnson, M., \& Valverde, L. M. (2014). Analyzing Adaptive Expertise and Contextual Exercise in Computer-Aided Design. Computer-Aided Design and Applications, 11(5), $597-607$.

[8] Cole, M., \& Miyake, N. 2006. Remembering Giyoo Hatano. Journal of the Learning Sciences, 13(3), 429-430.

[9] Hatano, G., \& Oura, Y. (2003). Commentary: Reconceptualizing school learning using insight from expertise research. Educational Researcher, 32(8), 26-29.

[10]Piaget, J. (1952). The origin of intelligence in children. New York: International University Press.

[11] Wineburg, S.: Reading Abraham Lincoln: an expert/expert study in the interpretation of historical texts, Cognitive Science, 22(3), 1998, 319-346.

[12] Hatano, G., \& Inagaki, K. (1986). Two courses of expertise. In H. Stevenson, H. Azuma, \& K. Hakuta (Eds.), Child development and education in Japan. New York: Freeman.

[13] Martin, T., Rayne, K., Kemp, N. J., Hart, J., \& Diller, K. R. (2005). Teaching for adaptive expertise in biomedical engineering ethics. Science and Engineering Ethics, 11(2), 257-276.

[14] Martin, T.; Benton, T.; Ko, P.(2010). "Transfer of Adaptive Expertise to Transform Engineering

Education", 09/01/2009-08/31/2010, "Conference Proceedings of the 2010 Annual Meeting of the American Society for Engineering Education 2010".

[15] Walker, J. M.T., Cordray, D. S., King, P. H. \& Brophy, S. P. (2006). Design scenarios for assessment of adaptive expertise. International Journal of Engaging Education, 22, 645-651.

[16] McKenna, A.F., Colgate, J.E., Olson, G.B. \& Carr, S.H. (2006). Exploring adaptive expertise as a target for engineering design education. ASME Proceedings $3^{\text {rd }}$ Symposium on International Design and Design Education. [17] Pandy, M.G., Petrosino, A.J., Austin, B.A., \& Barr, R.E. (2004). Assessing adaptive expertise in undergraduate biomechanics. Journal of Engineering Education, 93(3).

[18] Pierrakos O., \& Barrella, E., 2014, "On the Use of Design Reviews during a Two-Year Capstone Design Experience: The James Madison University Model.” 2014 Capstone Design Conference, Columbus, OH.

[19] Pierrakos O., Barrella E., Stoup K., (2015), “On the Impacts of Panel-based Technical Design Reviews: From Implementation to Mixed-Methods Evidence,” International Journal of Engineering Education, Capstone Design, Special Issue: Capstone Design Conference Select Papers, 31, 6(B), pp.1844-1859.

[20] Pierrakos O., Barrella E.M., Nagel R.L., Nagel J.K., Henriques J.J., Imholte D.D.**, June 2013, “An Innovative TwoYear Engineering Design Capstone Experience at James Madison University," $120^{\text {th }}$ ASEE Annual Conference \& Exposition, Atlanta, GA

[21] Ames, C. (1984). Achievement attributions and self-instructions under competitive and individualistic goal structures. Journal of educational psychology, 76(3), 478. 
[22] Lepper, M. R., \& Hodell, M. (1989). Intrinsic motivation in the classroom. Research on motivation in education, 3 , 73-105.

[23] Saville, B. K., Zinn, T. E., Neef, N. A., Norman, R. V., \& Ferreri, S. J. (2006). A comparison of interteaching and lecture in the college classroom.Journal of applied behavior analysis, 39(1), 49-61.

[24] Barker, C., Pistrang, N. and Elliott, R. (2002) Self-Report Methods, in Research Methods in Clinical Psychology: An Introduction for Students and Practitioners, Second Edition, John Wiley \& Sons, Ltd, Chichester, UK.

[25] Hawkshead J, Krousel-Wood MA. Techniques for measuring medication adherence in hypertensive patients in outpatient settings: advantages and limitations. Dis Manag Health Out. 2007;15(2):109-118.

[26] Gagné CGG. Improving self-report measures of non-adherence to HIV medications. Psychol Health.2005;20(6):803816.

[27] La Fleur J. Methods to measure patient compliance with medication regimens. J Pain Palliat Care

Pharmacother.2004;18(3):81-87.

[28] Turner BJ. Adherence to antiretroviral therapy by human immunodeficiency virus-infected patients. J Infect Dis.2002;185(Suppl 2):S143-S151.

[29] Farmer KC. Methods for measuring and monitoring medication regimen adherence in clinical trials and clinical practice. Clin Ther. 1999;21(6):1074-1090.

[30] Bennett-Johnson SB. Methodological issues in diabetes research. Measuring adherence. Diabetes Care.1992;15(11):1658-1667.

[31] Keller, D. (2005) Fast facts on data collection via direct measurements of behavior. Positive Environments, Network of Trainers 2005 Forum, 12(06). Retrieved from http://pdfzone.co/view?title=fast-f-data-collection-via-directmeasurements-of-behavior\&url=http://www.pent.ca.gov/beh/fa/datacollection_dk.pdf. 